\title{
Pego de surpresa: Improvisação na dança e na mente
}

\section{Taken by surprise: improvisation in dance and mind}

Susan Leigh Foster ${ }^{1}$ Tradução: Pedro Rodrigo Penuela Sanches ${ }^{2}$ 


\section{Resumo}

Tradução de texto da pesquisadora e artista da dança norte-americana Susan Leigh Foster, originalmente formulado como uma conferência dançada (apresentada em 1994) e mais tarde publicado no volume Taken by surprise: $A$ Dance Improvisation Reader (2003), organizado por Ann Cooper Albright e David Gere. $O$ texto organiza-se em "manifestos", que abordam diferentes camadas e aspectos da improvisação em dança, discutindo suas implicações para as teorias e discussões a respeito dos agenciamentos entre corpo e sujeito, das maneiras hegemônicas de se fazer história, das relações possíveis entre conhecido e desconhecido, entre outros aspectos fundamentais para a reflexão sobre corporeidade, dança, cena, em seus entrelaçamentos com questões filósoficas e políticas.

Palavras-chave: Improvisação; dança; agenciamento; corpo; história

\section{Abstract}

Translation into Portuguese of a work by Susan Leigh Foster, presented first as a danced lecture (in 1994), and later published in the book "Taken by surprise: A Dance Improvisation Reader", organized by Ann Cooper Albright and David Gere. The work is structured in "manifestos", which address different aspects of dance improvisation, regarding its implications in theories about body and self's agency, hegemonic ways of history making, relations between known and unknown, among other fundamental aspects for dance, body and performance inquiry, relating to philosophical and political issues.

Keywords: Improvisation; dance; agency; body; history

ISSN: 1414.5731

E-ISSN: 2358.6958

\footnotetext{
${ }^{1}$ Coreógrafa, dançaria e estudiosa. Professora da Universidade da Califórnia, Los Angeles (UCLA), no Departamento de Artes e Culturas do Mundo/Dança (USA). Desenvolve pesquisas nas áreas: história e teoria da dança, análise coreográfica e corporeidade.

${ }^{2}$ Doutorando pelo Programa de Pós-Graduação em Artes Cênicas da Escola de Comunicações e Artes da Universidade de São Paulo (PPGAC - ECA -USP), com bolsa da Fundação de Amparo à Pesquisa do Estado de São Paulo (FAPESP).pedro.penuela@gmail.com
} 
pego: 1. tempo passado, particípio passivo do verbo "pegar" (a dançarina aperta o microfone do pódio e o vira de costas) 2. ficar nas mãos de alguém ou em sua posse, poder, ou controle (ela cava o espaço, tomando-o com suas mãos, então subitamente, agarra as beiradas do pódio) 3. pegar, copular com, assumir, assegurar, adotar, acomodar, ou apreender (guia-o com atenção firme e então cuidadosa, desce-o até o chão, e então dá um passo para o lado do suporte agora derrubado para sua palestra)

de: $\mathrm{tchau}^{3}$ (acena em despedida e desaparece pelas beiradas do palco)

surpresa: 1. impulsionar com força através do inesperado (ela surge de repente do fundo, atrás, em meio a) 2. aturdir, espantar, maravilhar, pasmar (encolhe os ombros)

pego de surpresa: o inesperado toma o controle, resultando em um encontro sensual, vertiginoso, com o desconhecido, um encontro que levanta questões sobre como funcionam o desejo e o poder (o inesperado tomou o controle? bem, de certa forma. foi vertiginoso? quem pode dizer? levantou questões? sempre que um corpo está rastejando, deslizando, saltando, agachando, ondulando e chutando, ao mesmo tempo em que lendo em voz alta o texto de um maço de papeis que está agarrando seriamente, questões são levantadas)

improvisação: o que é composto de imediato ${ }^{4}$, no calor do momento.

\section{MANIFESTO (FENOMENOLOGICAMENTE)}

O dançarino, ao improvisar, transita entre o conhecido e o desconhecido, entre o familiar/confiável e o não-antecipado/imprevisível.

O conhecido inclui a gama de convenções comportamentais estabelecidas pelo contexto em que a ação ocorre, tais como as de uma esquina, um palco italiano, ou uma palestra. O conhecido inclui quaisquer referências estruturais predeterminadas que, de maneira ampla, delimitam as escolhas do corpo que improvisa, tais como a partitura para a performance, ou qualquer conjunto de regras determinadas de antemão: por exemplo, solos consecutivos de diferentes membros de um grupo. O conhecido também inclui uma predisposição corporal individual para mover-se por padrões de impulsos estabelecidos e tornados rotina por meio do treinamento em uma determinada tradição de dança, assim como a predileção do corpo por fazer certos tipos de seleção de um vocabulário ou uma sequência de movimentos. O conhecido inclui qualquer meio aliado com que a performance esteja em colaboração, tal como uma improvisação entre músicos e dançarinos, ou uma improvisação que aborda o espaço em que a ação ocorre como um participante ativo. $O$ conhecido inclui o que já aconteceu anteriormente na ação ${ }^{5}$ de improvisar.

O desconhecido é precisamente isso e mais. É o que era anteriormente inimaginável, o que podemos não ter pensado em fazer em seguida. A improvisação nos pressiona para estender para dentro, expandir para além, desprender-nos daquilo que era conhecido. Ela nos encoraja ou mesmo nos força a ser "pegos de surpresa". Mas não poderíamos jamais conseguir esse encontro com o desconhecido sem envolver o conhecido.

\footnotetext{
${ }^{3}$ Em inglês, se estabelece uma ressonância/paronomásia entre by (preposição "por") e bye (tchau, adeus) (N. T.)

${ }^{4}$ A autora utiliza o termo extemporaneous, que, em Inglês tem o significado de algo que é feito sem preparação prévia (significado inusual para o termo "extemporâneo" em Português, mais ligado à ideia de "atrasado, fora do tempo, inoportuno, etc" - significados diferentes daquele do texto original). (N. T.)

${ }^{5}$ Em alguns casos, optamos por traduzir o termo performance por "ação", enfatizando seu caráter mais corriqueiro, na língua inglesa, do que usualmente o anglicismo em português parece indicar. No entanto, a palavra performance envolve além da noção de ação, sempre em algum grau também a ideia de mostrar, apresentar. (N. T.)
} 


\section{MANIFESTO (HISTORICAMENTE)}

O improvisado é o que se esquiva da história. A performance de qualquer ação, não importa quão predeterminada esteja nas mentes dos que a executam e dos que a testemunham, contém um elemento de improvisação. Aquele momento de hesitação, enquanto se contempla como, exatamente, executar uma ação já profundamente conhecida, denuncia a presença da ação improvisada. É essa plenitude repleta de suspense do não-tão-conhecido o que dá à cena ao vivo seu brilho especial.

A história, contudo, segue a trilha exclusivamente do conhecido. Ela foca nas ações humanas reiteradas com frequência suficiente para tornarem-se padrões de comportamento. Dessa multidão de padrões, ela escolhe aquelas ações que deixam para trás algum resíduo permanente documentando seus efeitos. E dentre essa pletora de documentação, ela considera os traços que se prestam a ser traduzidos para o discurso escrito.

Os historiadores tipicamente suprimem a improvisação que ocorre consistentemente em todas as ações humanas. Eles também negam a improvisação do historiador, que seleciona e interage com toda a documentação do passado, em uma tentativa de decifrar a mudança ao longo do tempo. A reflexão histórica tem negligenciado a questão de como certas ações deslizam facilmente por campos representacionais até o registro histórico enquanto outras são persistentemente despercebidas. Como a história seria se ela considerasse o fato da improvisação? Como se pareceria uma história da dança improvisada?

A história nos informa que a coreógrafa e dançarina Marie Sallé apresentou sua versão radical da narrativa de Pigmaleão em Londres, em 1734. Radical porque ela aparecia sem espartilho ou peruca, e porque ela usava a pantomima para contar a história, sem a ajuda de texto falado ou cantado. De acordo com um espectador cuja descrição do balé foi publicada ${ }^{6}$, ela apareceu como Galateia e dançou um diálogo com seu escultor/criador no qual ele demonstrava frases simples, que ela não só dominava imediatamente, mas também ornamentava e melhorava, assim estimulando - o a apresentar a próxima frase. Imagine se esse diálogo fosse improvisado. Imagine a confiança que necessariamente ele teria de ter mostrado enquanto Sallé apresentava uma resposta surpreendente, uma que exigia dele pensar rápido. Imagine o suspense e o envolvimento que os espectadores teriam tido ao sentir a imprevisibilidade dessa troca. Talvez os dois dançarinos tenham combinado anterioramente improvisar seu dueto. Talvez Sallé, animada pelo óbvio sucesso de sua produção, introduziu elementos improvisados na noite de estreia. Talvez sua iniciativa audaciosa cresceu em performances subsequentes até chegar a um diálogo totalmente improvisado. Talvez nada disso tenha acontecido. Mas talvez tenha.

A história informa que Richard Bull, Cynthia Novack e Peentz Dubble, membros do Richard Bull Dance Theatre [Teatro de Dança de Richard Bull], participaram da performance Making and Doing ${ }^{7}$ em Nova York, em 1985. De acordo com a crítica, essa

\footnotetext{
${ }^{6} \mathrm{M}^{\star * *}$. Mercure de France. Abril de 1734, pp. 770-72. Para mais informações sobre Sallé, ver sua biografia, escrita por Emile Dacier, Une danseuse de l'Opera sous Louis XV: Mlle. Sallé (1707-1756) (Paris: Plon-Nourrit et Cie, 1909). Para uma maior discussão de seu Pigmaleão, ver meu Choreography and Narrative: Ballet's Staging of Story and Desire (Bloomington: Indiana University Press, 1996).

${ }^{7}$ Ambos os verbos podem ser traduzidos em português como "fazer", sendo que "to make" implica na ideia de produzir, fabricar, conceber, criar e "to do", implica em agir, executar, atuar. (N. T.)
} 
peça foi "um exercício de inventar movimentos e então recordá-los precisamente."8 Mas o que isso quer dizer e como funcionou? Como alguém que viu a apresentação e também participou de uma versão anterior da peça, ofereço esta análise: guiados pela partitura de Richard Bull, os coreógrafos-dançarinos, como se conduzissem um ensaio, executam exercícios de aquecimento, falam sobre suas preparações, e então ensaiam parte de uma "dança", cada um em um solo, juntando-se em um finale em uníssimo. Esta primeira seção da dança, durando sete ou oito minutos, é então repetida com música. Os dançarinos não falam mais, mas repetem toda a sua interação, incluindo gestos casuais de conversação e expressões faciais. Eles então se lançam a uma terceira repetição da "dança de ensaio", sem música, mas com as falas originais, enquanto as luzes vão se apagando devagar para terminar a dança. Ao conduzir os espectadores por um ensaio presumido, e então re-presentar esse ensaio com música, Making and Doing propositalmente enquadra todos os movimentos - os alongamentos de um aquecimento, marcas e gestos casuais, a execução virtuosística de frases ritmicamente complexas - como dança. A peça contraria as expectativas dos espectadores, em parte, 1. por apresentar um ensaio no palco e em parte, 2. por delinear a expressividade de cada mínimo gesto, quando é feito junto com música. Executando fielmente a temporalidade [timing] original de um ensaio, os dançarinos criam congruências e dissonâncias intrigantes com a estrutura musical, conforme trabalham para transformar tanto o movimento cotidiano como o virtuoso em dança.

Apesar de a estrutura em três partes de ensaio, repetição com música, e segunda repetição guiar cada performance, os movimentos específicos são sempre improvisados. Todos os três dançarinos co-coreografando a peça geram novas sequências em cada apresentação, inovando em relação à partitura, às ações imprevisíveis dos outros dançarinos, e a seu julgamento estético em relação às necessidades gerais da dança conforme ela se desenvolve. $E$ tudo isso é feito enquanto tentam lembrar tudo o que estão fazendo na parte 1, para poder repetir nas partes 2 e 3 . A improvisação é também requerida nessas seções, à medida que os dançarinos esquecem porções do material ou diferem em seu ritmo [timing] de repetir o já feito. Ao longo desse processo, os coreógrafos-dançarinos respondem ao conhecido e ao desconhecido uns nos outros, e ao conhecido e ao desconhecido em relação ao que faz uma dança ser boa. Na noite em que vi a performance, a tensão entre o que estava acontecendo, o que acontecia em seguida, e como determinada escolha influenciava a forma completa da peça eletrizava a apresentação. Os expectadores podiam assitir a uma performance tanto de uma dança sendo apresentada como de uma dança sendo criada, ao mesmo tempo.

Making and Doing, como o Pigmaleão de Sallé, comentam reflexivamente a dança e o fazer artístico. Além disso, enquanto Sallé, como Galateia, corporificava uma criação artística cujo criador a assistiu ganhar vida, Bull, Novack e Dubble, cada um, habitavam os papeis de coreógrafo e dançarino. O diálogo de Sallé com o escultor envolvia a introdução de frases de movimento, a repetição dessas frases, e a variação nos passos e frases, que podia levar à geração de novos movimentos. Making and Doing também envolvia a repetição, mas de uma seção inteira, comprida, da

${ }^{8}$ Elizabeth Zimmer, "Richard Bull Dance Theatre", Dance Magazine, (Abril, 1985): 37. 
dança. Sallé e seu parceiro foram guiados em sua improvisação pelos códigos de graciosidade na dança, de estrutura de fraseado e métrica musical, e pela necessidade de responder com astúcia e agilidade às iniciativas um do outro. Eles selecionaram e combinaram passos de dentro de um vocabulário altamente delimitado de passos de dança. Bull, Novack e Dubble, guiados por um cenário geral, mas sem especificações métricas, tentaram coreografar uma dança de oito minutos, cheia de exercícios preparatórios, assim como movimentos de dança moderna. Eles trabalharam para criar um trio de variação dinâmica, interações intrigantes, e integridade estrutural que pudesse sustentar o teste de ser revisto duas vezes. Nenhuma dessas danças anunciou antes que algumas partes seriam improvisadas. Os espectadores lentamente deduziram o fato da composição espontânea, devido à qualidade particular de alerta que os dançarinos manifestavam enquanto eles criavam, assim como executavam, a dança.

O que esses exemplos nos dizem? O fato da improvisação pode ser informativo? Há maneiras de comparar diferentes combinações e acessar os efeitos únicos do conhecido e do desconhecido usados em várias abordagens da improvisação? Como a tentativa de incluir o improvisado pode alterar o curso da reflexão histórica? Há maneiras de escrever sobre improvisação que estabelecem sua significação e impacto, sem filtrar dela o maravilhamento e a consciência crítica que ela inesperadamente produz?

\section{MANIFESTO (DISCURSIVAMENTE)}

Nos parcos discursos descrevendo a experiência da improvisação que a história nos deixou, os termos "mente" e "corpo" frequentemente ocupam os lugares do conhecido e do desconhecido. Nós lemos que a improvisação é o processo de abandonar a atividade da mente, de modo que o corpo possa fazer seus movimentos de sua própria maneira imprevisível. Mas essa descrição é um engodo, tão inútil quanto imprecisa; é claro que toda articulação corporal é plena da presença da mente. Cada travessia de segmentos do corpo no espaço, quer direta ou sinuosamente, é preenchida de pensamento. Cada modulação corporal do esforço pensa; cada dilatação na tensão pensa; cada explosão errática ou ondulação da energia pensa. Cada fraseado com acentuações, torção em aceleração, ou pausa momentânea é uma instância de pensamento. Conceituada dessa maneira, a ação corporal constitui um gênero de discurso.

Se, então, a articulação corporal é plenamente mental [mindful], que tipo de mente ${ }^{9}$ a improvisação espera transcender? A capacidade de avaliar e censurar? Mesmo essas faculdades permanecem ativas durante a improvisação. A improvisação envolve momentos em que se pensa antes sobre o que se vai fazer, outros momentos em que as ações parecem mover-se mais rápido do que podem ser registradas na consciência analítica, e ainda outros momentos em que se tem a ideia do que está por vir no exato momento em que se executa tal ideia. E ainda, tanto a mudança deliberada do curso das coisas, quanto o pegar carona nesse curso, ambos são mentais e corporais. Mais do que suprimir qualquer função da mente, a mente corporificada da

\footnotetext{
${ }^{9}$ A palavra usada pela autora é mindfulness, em outros contextos traduzida como "atenção plena". (N. T.)
} 
improvisação reúne um tipo de hiperconsciência das relações entre a ação imediata e a forma geral, entre aquilo que está para acontecer ou está acontecendo e aquilo que já aconteceu ou que vai acontecer.

Também lemos nos discursos sobre a improvisação a alegação de que esta, por causa de sua espontaneidade corporal, não requer nenhuma técnica. Essa, também, é uma acusação infundada e enganosa. A improvisação faz demandas técnicas rigorosas ao performer ${ }^{10}$. Ela pressupõe uma articulação no corpo por meio da qual o conhecido e o desconhecido encontrarão expressão. Ela envolve uma porosidade vigilante em direção ao desconhecido, uma postura que só pode ser adquirida por meio da prática intensiva. Ela depende da familiaridade lúcida do performer com os princípios da composição. (Afinal, improvisar é compôr no momento, e a composição é um arranjo em uma proporção ou relação apropriadas).

A improvisação também demanda uma consciência reflexiva de quando o conhecido está se tornando um estereótipo, uma rotina ao invés de um caminho, e ela insiste na coragem e na perspicácia (talentos também adquiridos), para recalibrar o conhecido e o desconhecido enquanto a performance se desenrola.

A improvisação, portanto, não envolve um silenciamento da mente para que o corpo "fale". Ao contrário, a improvisação faz girarem tanto o corpo como a mente para a apreensão de novas relacionalidades.

\section{MANIFESTO (ANALITICAMENTE)}

Na forma de sua função, a improvisação lembra muito de perto uma categoria gramatical encontrada nas formas verbais de muitas línguas (incluindo o Grego clássico) conhecida como voz média. Neste tipo de uso do verbo em particular - e os verbos são, dentre todos os elementos linguísticos, os mais próximos do dançar os eventos não acontecem nem na voz ativa nem na voz passiva. O sujeito não age, tampouco recebe uma ação. Um equivalente próximo na língua inglesa (que não tem voz média) a essa voz não-ativa/não-passiva é a frase "merda acontece".

A experiência dessa voz média é talvez mais palpável quando se improvisa com outra pessoa. Muitos de nós disfrutaram da experiência de nem conduzir nem seguir, mas, ao invés disso, mover-se com, e ser movido por outro corpo. O peso e momentum de um corpo fluem para e com a forma da trajetória de um outro corpo, fazendo uma co-moção dos dois corpos. Ou, ambos os corpos, levados pelo mesmo impulso, movem-se em tandem, sem se tocar fisicamente, mas tocados por uma sensibilidade compartilhada sobre as necessidades da composição. Ou, cada corpo, conhecendo tão intimamente as particularidades e inclinações do outro, simplesmente encarna o parceiro. De novo, ao longo dessa experiência, há muitos momentos em que alguém conduz ou é conduzido, então bifurcando a ação em iniciação e resposta. Mas há também momentos espetacularmente lúcidos, quando as ações de ambos os corpos coordenam-se e sincronizam-se em uma orquestração espontânea.

O conceito de uma operação que não é nem ativa nem passiva, tal como a voz

\footnotetext{
10 "Performer" entendido aqui em sentido amplo, como aquele que performa, isto é, que age e apresenta a ação, neste caso, da improvisação. Não somente o artista da arte da performance. (N. T.)
} 
média, desafia profundamenteos valores culturais hegemônicos que persistentemente forçam uma escolha entre um desses dois polos. A maioria das teorias sobre a significação da ação humana dependem da concepção de um sujeito individual e isolado, localizado dentro de um corpo, que controla e manipula para conseguir auto-expressão e preencher necessidades individuais. O sujeito dentro do corpo diz ao corpo o que fazer, e o corpo executa essas ordens, às vezes de maneira relutante e inadequada, ou desviante, mas nunca de maneira autônoma ${ }^{11}$. Outras teorias investem o estado e o capital com o poder de transformar o corpo/sujeito em uma máquina desejante, cujos impulsos todos somente estimulam o crescimento do capital e do poder, que tudo consome, do estado. Nesses modelos, todas as escolhas individuais meramente mantêm a aparência de independência. Sob um exame minuncioso, porém, a estruturação das iniciativas individuais eleva sua cooptação prévia pelos canais governamentais ou capitalistas, por meio dos quais o poder exerce seu controle $\mathrm{e}^{12}$.

Nesses dois modelos do agenciamento humano, aquele segundo o qual o sujeito diz ao corpo o que fazer, ou aquele segundo o qual tanto o corpo como o sujeito são subsumidos por forças políticas e econômicas maiores, o corpo é relegado ao status de objeto instrumental. Roubado de toda vitalidade e, mais ainda, da capacidade de agenciamento, permanece como uma coisa muda e surda. A experiência de improvisar, contudo, estabelece a possibilidade de uma teoria alternativa do agenciamento corporal, uma que refuta a mera instrumentalidade do corpo e sugere formulações outras de como acontecem os agenciamentos individuais e coletivos.

A improvisação gera uma experiência de corpo em que este inicia, cria e explora ludicamente seu próprio potencial físico e semântico. O corpo pensante e criador se engaja na ação. A presença deste corpo, cultivado durante aulas de dança que ampliam a destreza nas habilidades improvisacionais, é o que recalibra ego e superego, crítica e comicidade, atentividade e ativismo, e impulsos individualistas e comunitários para criar uma voz média entre eles. Esse corpo instigador, assim como responsivo, sustenta o desenvolvimento da consciência como uma hiperconsciência de relacionalidades. Cada próximo momento da improvisação, cheio de posicionamentos possíveis, desenvolve sua própria significação coreográfica à medida que todas as ações dos participantes trazem a performance para a proporção ou relação apropriada. Durante esse trabalho lúdico, a consicência transita entre os pontos de vista de: sujeito em relação a grupo, corpo em relação a corpo, movimento em relação a espaço e tempo, passado em relação a presente, fragmento em relação ao todo em desenvolvimento. Compartilhada por todos os improvisadores em determinada performance, essa consciência corporificada permite fazer a dança e, ao mesmo tempo, a dança fazendo-se a si mesma.

O poder circula através das ações coletivas de tal improvisação. Ele nunca tem a oportunidade de permanecer em uma articulação específica do corpo, ou pousar no lugar de um indivíduo em particular, ou agachar entre certa porção do grupo. $O$ poder é repetidamente "pego de surpresa", de modo que não possa nunca alojar-se dentro de um elemento estrutural estático que pudesse permiti-lo flexionar-se em

\footnotetext{
${ }^{11}$ Esse modelo de agenciamento individual está na base das teorias do contrato social descendentes da teoria de Jean-Jacques Rousseau.

${ }^{12}$ Michel Foucault foi um dos primeiros teóricos da política a desenvolver esse tipo de perspectiva sobre 0 corpo e 0 agenciamento.
} 
hierarquias de dominação e controle. Na improvisação, o poder só pode continuar em movimento, correndo tão rápido quanto possa para emparceirar, para empoderar os performers, nunca superando-os.

A improvisação empodera aqueles que a testemunham, assim como aqueles que a executam. Ao assistir a uma improvisação, a consciência se expande para além de uma recepção passiva de um evento, em direção a um engajamento ativo no verdadeiro fazer deste evento. Os espectadores participam com os performers do campo aberto de escolhas possíveis e da construção e seleção dessas escolhas, através das quais o significado é determinado. $O$ jogo em voz média de desejo e poder envolve o público e convida à participação no acontecimento.

O remanejamento de poder e desejo que tem lugar durante a improvisação, a nova concepção de agenciamento humano articulada durante a improvisação, e a identidade especial do corpo descoberta por meio da improvisação - são todos entendimentos [insights] de importância crucial. Eles impactam nossa compreensão do agenciamento político e histórico, e nos dão uma fonte muito rica de táticas para navegar no próximo milênio.

\section{MANIFESTO (ESPISTEMOLOGICAMENTE)}

$\mathrm{Na}$ apresentação original desse ensaio, eu li em voz alta, falei improvisadamente, e improvisei uma coreografia, falando e dançando simultaneamente ${ }^{13}$. Havia sido pedido a mim para escrever uma palestra sobre improvisação, para fixar no papel certos pensamentos sobre o imprevisível e desenvolver essas ideias verbais sobre a dança para um público. Duas contradições me seguraram em suas garras: (1) que um discurso escrito sobre a improvisação não pode jamais incorporar sua espontaneidade essencial; e (2) que a tradução da dança para a escrita pode erodir o poder e significação do corpo movendo-se improvisadamente. A fim de sair da primeira contradição, eu não apenas adicionei comentários improvisados; eu organizei a escrita em trajetórias de indagação, manifestos, cujos fins em aberto podem convidar a futuros diálogos improvisados. A fim de escapar da segunda, eu improvisei uma dança que às vezes ilustrava e às vezes comentava a fala. E ainda outras vezes, a dança resolutamente perseguia seus próprios interesses, desligados da fala que estava acontecendo. Desse modo, eu espero ter criado uma co-moção entre dois discursos, o falado e o dançado, à medida em que eram compostos, mais ou menos espontaneamente, juntos.

Esse ensaio é um gesto na direção desta co-moção, seu corpo tensiona-se entre a prosa convencional e outros tipos de escrita, que podem retratar mais precisamente a interação entre as palavras e a dança (rolando a manga da camisa pela décima quarta vez, a dançarina sorri). Esse ensaio tem a intenção de aclarar um espaço onde coreógrafos e acadêmicos, juntos e também separados, podem começar a considerar os trabalhos da improvisação na dança e na história (ondulando, enrolando-se para baixo, quase piscando). Uma vez iniciada, tal reflexão falada-dançada pode bem

\footnotetext{
${ }^{13}$ A apresentação aconteceu como fala principal da conferência "Taken by surprise: Improvisation in Dance and Mind" [Pego de surpresa: improvisação na dança e na mente], organizada por David Gere e Ellen Webb, no Talking Dance Project [Projeto Dança Falante ou Falando sobre Dança], em Berkeley, Califórnia, 10-11 de Junho, 1994.
} 
durar por um tempo muito longo (ela anda até o pódio e o coloca na posição correta antes de sair do palco).

\section{Referência da publicação original}

FOSTER, Susan Leigh. Taken by surprise: Improvisation in Dance and Mind. In: ALBRIGHT, Ann Cooper \& GERE, David (orgs.). Taken by surprise: A Dance Improvisation Reader. Middletown: Wesleyan University Press, 2003, p. 3-10.

Recebido em: $14 / 04 / 2017$

Aprovado em: 25/04/2017 